\title{
O DESENVOLVIMENTO TERRITORIAL PARA AVALIAÇÃO DE POLÍTICAS PÚBLICAS EXEMPLO DO ASSENTAMENTO DE UMA FAZENDA EM TOCANTINS (BRASIL)*
}

\author{
José CARLos DE MirandA ${ }^{1}$
}

\begin{abstract}
Resumo - O objetivo desta nota é discutir o desenvolvimento territorial como alternativa metodológica para a avaliação das políticas públicas que tiveram como palco o desmembramento de uma fazenda, de nome Coqueirinho, comprada pelo Governo do Estado, no município de Palmas/TO, na qual uma parte foi doada para a instalação de um assentamento de ocupação agrária, a partir de 1993. Esta apresentação faz parte de uma pesquisa sobre o sistema organizacional da produção agrícola, tendo como foco de observação a experiência vivida no meio destes trabalhadores rurais.

Para elaboração deste texto utilizámos os dados das fontes citadas no decorrer da dissertação, bem como as informações levantadas pela pesquisa. Neste texto apresentamos as características gerais das políticas públicas da década de noventa até hoje, focalizando duas posições essencialmente diferentes uma da outra, que tiveram lugar em duas conjunturas igualmente diversas, tanto do ponto de vista econômico como político. Por fim apresentamos alguns elementos metodológicos que, associados à discussão do tema do desenvolvimento territorial, poderão dar consistência aos argumentos apresentados.
\end{abstract}

Palavras-chave: Agricultura familiar, assentamento, ordenamento territorial.

\begin{abstract}
A TERRITORIAL DEVELOPMENT APPROACH TO THE EVALUATION OF THE PUBLIC POLICIES IMPLEMENTED IN THE "COQUEIRINHO" AGRICULTURAL SETTLEMENT, MUNicipality of Palmas (STATE of Tocantins, BraziL). The aim of this article is to discuss territorial development as an alternative methodology for evaluating the public policies that were implemented following the collapse and take-over by the state of the "Coqueirinho" agricultural estate (municipality of Palmas, state of Tocantins, Brazil), a part of which was set aside in 1993 for the settlement of agricultural workers. The findings presented here constitute some of the results of a research project on organizational systems of agricultural production, with a special focus on the
\end{abstract}

* Recebido: 10/03/2007. Revisto: 30/11/2007. Aceite: 19/12/2007.

1 Mestre em Geografia - UFMS. E-mail: josecarlos@cpaq.ufms.br

Este texto foi produzido a partir dos resultados da pesquisa de campo no Assentamento Coqueirinho - objeto de estudo do trabalho dissertativo, na área de Geografia, do programa de Pós-graduação da Universidade Federal do Mato Grosso do Sul. 
ethnographic observation of the experiences of rural workers. The article draws on secondary sources as well as on primary data collected during fieldwork. The general characteristics of the public policies implemented between the 1990s and the present day are presented and discussed, and special mention is made to two radically different policies that were implemented in also very different economic and political contexts. Additionally, a number of methodological issues are raised in relation to territorial development, with a view to providing with added consistency the arguments that are put forth.

Key words: Family agriculture, settlement, land use.

Résumé - Le lotissement PARTIEL De LA FAZENDA Coqueirinho, vu DANS LE CADRE DE L'ORgAnisATION du NOUVEL ÉtAT du TocAntins (BRÉSil). Une partie de cette fazenda, achetée par le Gouvernement du Tocantins, a été distribuée en 1993 à des travailleurs ruraux sans terre. On a observé leur comportement au cours des premières années d'installation: d'abord la satisfaction de leurs propres besoins alimentaires, ensuite la recherche de profits basés sur la vente. On cite la bibliographie qui a servi de base à la dissertation réalisée et on discute les divers aspects méthodologiques qu'implique l'évaluation de la politique suivie par le Gouvernement.

Mots-clés: Agriculture familiale, lotissement, organisation territoriale.

\section{INTRODUÇÃO}

Na história recente de Palmas observa-se, a partir da década de noventa, ou seja, em todo o período de ocupação das terras do Estado recém criado, uma política de incentivo à ocupação territorial, de grande repercussão nacional. Em um segundo momento, ocorreu a implantação do Assentamento Coqueirinho. Nesta nota trata-se, inicialmente, de levantar os problemas de cada fase e propor uma metodologia de comparação entre as políticas públicas que foram adotadas para o assentamento. Procuramos fazer uma descrição geral de cada conjuntura e apontar os problemas ligados a uma e a outra política. Ao final pretende-se argüir a necessidade da perspectiva do desenvolvimento territorial sustentável como elemento de balizamento para as políticas públicas voltadas ao desenvolvimento com fins sociais. Começamos por apresentar um esboço histórico das transformações ocorridas no território estudado, Palmas/TO.

Como resposta aos pedidos de terras dos migrantes que se instalaram no território estudado, o governo estadual, sofrendo também a pressão dos movimentos sociais, comprou a Fazenda Coqueirinho e destinou uma parte da área adquirida para o atendimento destes pedidos, um total de 173 alqueires, um alqueire por cada interessado. Deste modo, o aparecimento do assentamento cumpre um duplo papel histórico: 1) minimiza os efeitos sociais e políticos da população flutuante, consubstanciada na instalação da capital do Estado; 2) cria uma alternativa de emprego e renda para a população rural instalada, abrindo assim espaço para uma nova configuração do território.

Antes de qualquer consideração sobre a importância ou o desempenho econômico do assentamento, é necessário fazer duas considerações preliminares. Em primeiro lugar, o assentamento surge não em decorrência de uma política propositiva de reforma agrária, mas como resultado do interesse daqueles que procuraram o Estado em busca de 
um lugar para morar e trabalhar. Assim, a "reforma agrária", no caso, busca uma alternativa à procura econômica da capital emergente. A ação ocupacionista, aparece com o objetivo de criar uma política social de desenvolvimento e de mitigação dos efeitos sociais e econômicos de um projeto mais macro, amplamente apoiado pelo Estado. Em segundo lugar, é preciso registrar que a criação deste assentamento só foi possível mediante uma ampla e eficiente mobilização da comunidade local, aproveitando a conjuntura da criação do Estado e pelo arco de desenvolvimento da política gerada pelo governo federal.

Tomando o território de Palmas como lócus de observação e análise das políticas públicas, deparámo-nos, de imediato, com uma diferença fundamental nos diversos projetos de desenvolvimento implantados em outros territórios sob o patrocínio do Estado. Ou seja, diferenças fundamentais na direção e formatação das políticas públicas nacionais que podem emblematicamente ser agrupadas: de um lado políticas de estímulo e fomento ao agronegócio, aos grandes proprietários, através do Ministério da Agricultura; de outro, políticas de apoio à agricultura familiar, através do Ministério do Desenvolvimento Agrário.

A discussão do desenvolvimento territorial passa, portanto, por esta avaliação: o engajamento ativo do Estado, através de políticas públicas generosas voltadas ao fomento do grande empresariado e o engajamento do Estado com políticas públicas voltadas à implantação do Coqueirinho. Enfim, é preciso avaliar o processo histórico do surgimento desse assentamento até porque o povoamento da capital obrigava o aumento da produtividade agrícola na produção de alimentos. O Estado foi bastante benevolente na liberação do parcelamento para a instalação do assentamento sem levar em conta as sérias limitações topográficas da região que tornam economicamente inviável a produção em larga escala de alimentos no território.

\section{A AVALIAÇÃO ECONÔMICA DO ASSENTAMENTO}

Um fato importante a ser destacado, com a instalação do assentamento e a busca da sustentabilidade, estruturação e o re-ordenamento do território é a forma como os assentados desenvolveram as primeiras culturas. A princípio, as lavouras de subsistência: feijão, milho, mandioca, outros tubérculos e fruteiras. Não houve um planejamento oficial, uma definição prévia baseada em um zoneamento agrícola, mas na primeira etapa a palavra de ordem foi cultivar, na medida do possível, lavouras de subsistência. Com isso, o território passa a produzir géneros alimentares. Compreende-se, assim, a importância estratégica desses produtos na agricultura familiar; o assentamento resgatou aos poucos essas bases. O primeiro passo foi, portanto, a reconversão das áreas, de cerrado para a policultura de alimentos (Moreira et al., 2001).

Mas este processo que ocorreu apenas com a doação dos lotes e sem a intervenção ou planejamento posterior do Estado, não poderia ter dado tão certo nem trazido resultados tão bons quanto se fosse planejado e direcionado a este objetivo, a fixação do homem. Os assentados incorporaram a proposta para a qual o assentamento foi criado: segurança alimentar para os trabalhadores instalados e comercialização do excedente.

Uma vez demarcados os lotes e feito um esforço quase que espontâneo na direção de culturas alimentares, como foi então se desenhando a estrutura produtiva dos lotes? Tratava-se de encontrar cultivos comerciais, cuja demanda fosse assegurada e que garantissem uma boa renda aos assentados. Qual o caminho seguido? 
A existência de plantios de mandioca na região, com escoamento assegurado para outras cidades foi a alternativa mais segura: os lotes foram rapidamente cobertos de mandiocais, com variedade diversa, de grande produtividade e aceitação pelo comércio comprador. Ao lado da mandioca, outras plantas frutíferas como o cajueiro, o coqueiro e a manga, como cultivos secundários, foram ocupando espaço sem, contudo, assumir a importância econômica que a mandioca começou a representar para os assentados. Cabe complementar também que alguns assentados do Assentamento Coqueirinho obtiveram crédito para a criação de gado leiteiro, o que possibilitou a associação entre lavouras temporárias, fruticultura e gado.

Este consórcio tem permitido a acumulação monetária de algumas famílias, fato que não pode ser generalizado para todo o assentamento. $\mathrm{O}$ cultivo da mandioca, no assentamento, tem representado um grande limite para o desenvolvimento, na medida em que o tamanho das propriedades, não permite a ampliação da área plantada nem a busca de novos mercados, limitando a distribuição de renda, sobretudo devido à dependência com relação aos compradores, no caso, atravessadores que vêm buscar o produto na propriedade. Neste contexto, é grande o interesse da parte do assentado em cultivar outros produtos comercializáveis. Em vários lotes têm-se plantado outros cultivares para obtenção de excedentes de produtos fora da subsistência; para aqueles assentados que não alcançam este nível de resposta à demanda emergente resta-lhes a venda da propriedade. Porém a venda dos lotes implica a continuação da produção pelos novos proprietários que, impondo novas tecnologias, seguem o sistema produtivo do território instalado com a implantação de novas lavouras familiares.

O processo de implantação das lavouras familiares, no Assentamento Coqueirinho, obedece, então, a determinados fatores na escolha das culturas agrícolas; entre eles destacamos:

- As espécies conhecidas dos assentados que já faziam parte da cultura de plantio dos mesmos;

- Os conhecimentos das famílias quanto à produção e ao manejo das sementes e mudas das espécies a serem cultivadas;

- Experiências bem sucedidas com os cultivares;

- Correspondência entre a produção e a demanda.

A experiência deste processo, vivido no assentamento, mostra que a alternativa é desenvolver as potencialidades inscritas no rol do saber local e das possibilidades em termos de solo e água. No entanto, só alguns cultivos se apresentam como "viáveis". Estes se materializam nas práticas de manejo, na medida em que são compartilhados e difundidos pela comunidade, construindo assim um "saber comunitário". A assistência técnica, se desenvolvida pelo Estado, pode potencializar esse conhecimento local e contribuir com o repasse geracional desses saberes. É importante destacar, também, a importância da comercialização dos produtos do assentamento. Não tem sentido pensar a reforma agrária apenas como uma forma de obtenção de segurança alimentar. As dificuldades encontradas fora do campo são facilmente superadas quando qualquer agricultor tem acesso a um pedaço de chão, mesmo de dimensões reduzidas. Depois de tomar posse do lote e fazer as primeiras culturas, com a alimentação em casa garantida, a preocupação passa a ser a comercialização do excedente.

Examinemos então como é feita a comercialização da produção no Assentamento Coqueirinho. Constatou-se a ausência da ação de atravessadores, que dominam, em 
outros lugares, boa parte do processo de comercialização. O controle da comercialização pelos assentados representa o grande mérito da agricultura familiar, que se pode observar no Coqueirinho, muito embora os atravessadores colaborem, muitas vezes, para o nivelamento dos preços no mercado.

\section{CONSIDERAÇÕES FINAIS}

As questões colocadas não têm resposta clara e apontam para as parcerias que se têm se desenvolvido em diversas direções: de um lado, parceiros oficiais e mais ou menos regulares; de outro parcerias construídas a partir de contatos e interesses eventuais. Como parceiros oficiais aparecem, o governo municipal e estadual, e em uma relação mais distante, menos regular, a Embrapa e as universidades. Numa série de contatos informais, decorrentes da própria identidade de interesses, construída ao longo do processo de instalação contam-se: o relacionamento com as igrejas, com os movimentos organizados e com simpatizantes. Dada a experiência acumulada neste assentamento, e sua capacidade de trabalho, pode-se concluir que os assentamentos que conseguirem construir parcerias comunitárias terão mais facilidades para superar as dificuldades que enfrentam, uma vez que a presença e atuação do Estado, órgão responsável pelos assentamentos é esporádica e incerta.

Em suma, a possibilidade do Desenvolvimento Territorial depende certamente da capacidade dos assentados de tomarem conhecimento dos novos desafios e dificuldades, e encontrarem as soluções mais eficazes. Se estes conseguirem influenciar o desenvolvimento regional em uma perspectiva sustentável (a médio e longo prazo) terão contribuído, também, para a recomposição do tecido social e político da própria região, dotando-a de uma nova identidade. Os assentamentos em áreas que parecem não possuir alternativas de desenvolvimento econômico, surgem como uma estratégia bastante promissora tanto do ponto de vista econômico, como cultural e político, mesmo quando o Estado se ausente, após a doação de pequenas parcelas das terras, e o sistema bancário não está presente. Mas é fundamental que os assentamentos se instalem próximos às cidades, como é o caso do Assentamento Coqueirinho.

\section{BIBLIOGRAFIA}

AMATUR - Agência de Meio Ambiente e Turismo de Palmas (2000) Diagnóstico turístico do distrito de Taquaruçu. Palmas - Tocantins. Prefeitura Municipal de Palmas.

Andrade A C de (1973) A terra e o homem no Nordeste. Ed. Brasiliense. 3. ${ }^{\text {a }}$ edição.

Arbués M P (2004) A migração e a construção de uma (nova) identidade regional: Gurupi (1958-1988). In Giraldin O (org.) A transformação histórica do Tocantins. Ed. UFG. 2. ${ }^{a}$ Edição, Goiânia.

Barbosa Y M (1999) As políticas territoriais e a criação do Estado do Tocantins. Dissertação de Doutoramento em Geografia. USP. São Paulo-SP.

Brandão C R (1981) Plantar, colher, comer. Ed. Graal. Rio de Janeiro.

BRASIL. Presidência da República. Comissão Interministerial para Preparação da Conferência das Nações Unidas sobre Meio Ambiente e Desenvolvimento (1991) O desafio do desenvolvimento sustentável. Cima, Brasília. 
Fernandes M (2002) Desenvolvimento sustentável - Antinomias de um conceito. Raízes. Revista de ciências econômicas e sociais, 21(02): 246-260.

Ferreira A (1995) Buarque de Holanda. Dicionário Básico de Língua Portuguesa. Nova Fronteira, Rio de Janeiro.

Cândido A (1987) Os parceiros do Rio Bonito: estudo sobre o caipira paulista e a transformação dos seus meios de vida. Livraria Duas Cidades, 7. Edição, São Paulo.

COMPANHIA DE SANEAMENTO DO TOCANTINS - SANEATINS (2006) Relatório do Monitoramento de vazão do Ribeirão Taquarussu Grande. Palmas.

Gomes H (1991) A produção do espaço geográfico no capitalismo. Contexto, 2. ${ }^{a}$ ed. São Paulo.

Holanda S B (2004) Raízes do Brasil. Ed. Companhia das Letras, São Paulo.

INCRA (2000) Nova Retrato da Agricultura Familiar: O Brasil Redescoberto. Ministério do Desenvolvimento Agrário, Brasília.

Leite S, et alii. (2004) Impactos dos Assentamentos: um estudo sobre o meio rural brasileiro. Editora da UNESP, São Paulo.

Leite S (org.) (2001) Politicas públicas e agricultura no Brasil. Editora da Universidade, Porto Alegre.

Moreira E, et alli. (2001) Impactos regionais da reforma agrária: o caso da Zona da Mata nordestina e do Brejo Paraibano. Relatório final de pesquisa.

Moreira E (1997) Por um pedaço de chão. Editora Universitária-UFPB, João Pessoa.

Nunes R (2000) Agricultura familiar: custos de transação, forma organizacional e eficiência. Dissertação de Doutoramento, Faculdade de Economia, Administração e Contabilidade da Universidade de São Paulo, São Paulo.

Oliveira A U (1997) Agricultura Camponesa no Brasil. Ed. Contexto, 3. ${ }^{a}$ Edição, São Paulo.

Oliveira A U (1986) Modo Capitalista de Produção e Agricultura. Série Princípios. Editora Ática.

Santos J E (1996) Taquaruçu: reconstruindo uma história através da memória (1940-1960). Dissertação de Mestrado em História, Universidade Federal de Pernambuco, Recife.

Santos M (1993) Metamorfose do espaço habitado. Hucitec, 3. ${ }^{a}$ Edição, São Paulo.

Santos M (1992) Espaço e Método. Ed. Nobel, 3. ${ }^{a}$ Edição, São Paulo.

Silva G (1996) A nova dinâmica da agricultura brasileira. Instituto de Economia, Unicamp, Campinas.

Silva J V B (2002) O direito de ficar na terra. Omissões do Estado e a construção de um novo sujeito coletivo de direitos. Dissertação de Mestrado, Universidade Federal de Campina Grande, Campina Grande.

Silva O B (1997) Breve história do Tocantins e de sua gente. Uma luta secular. 2. Edição, 1. ${ }^{a}$ Edição. Araguaína(TO), Fieto.

UNITINS (1999) Plano de manejo da sub-bacia do ribeirão Taquarussú Grande - TO. Palmas.

Veiga J E (1991) O desenvolvimento agrícola. Uma visão histórica. Hucitec, São Paulo.

Veiga J E, et al. (2001) O Brasil rural precisa de uma estratégia de desenvolvimento. Texto para discussão n. 1. Brasília, MDA/NEAD. 